\title{
In situ TEM analysis of a symmetric solid oxide cell in oxygen and vacuum-cation diffusion observations
}

Gualandris, Fabrizio; Simonsen, Søren Bredmose; Wagner, Jakob Birkedal; Sanna, Simone; Muto, S.; Kuhn, Luise Theil

\section{Published in:}

ECS Transactions

Link to article, DOI:

$10.1149 / 07542.0123$ ecst

Publication date:

2017

Document Version

Peer reviewed version

Link back to DTU Orbit

Citation (APA):

Gualandris, F., Simonsen, S. B., Wagner, J. B., Sanna, S., Muto, S., \& Kuhn, L. T. (2017). In situ TEM analysis of a symmetric solid oxide cell in oxygen and vacuum-cation diffusion observations. ECS Transactions, 75(42), 123-133. https://doi.org/10.1149/07542.0123ecst

\section{General rights}

Copyright and moral rights for the publications made accessible in the public portal are retained by the authors and/or other copyright owners and it is a condition of accessing publications that users recognise and abide by the legal requirements associated with these rights.

- Users may download and print one copy of any publication from the public portal for the purpose of private study or research.

- You may not further distribute the material or use it for any profit-making activity or commercial gain

- You may freely distribute the URL identifying the publication in the public portal 


\title{
In situ TEM analysis of a symmetric solid oxide cell in oxygen and vacuum - cation diffusion observations
}

\author{
F. Gualandris ${ }^{\mathrm{a}}$, S. B. Simonsen ${ }^{\mathrm{a}}$, J. B. Wagner ${ }^{\mathrm{b}}$, S. Sanna ${ }^{\mathrm{a}}$, S. Muto ${ }^{\mathrm{c}}$, L. Theil Kuhn ${ }^{\mathrm{a}}$ \\ ${ }^{a}$ DTU Energy, Technical University of Denmark, Roskilde 4000, DK \\ ${ }^{b}$ Center for Electron Nanoscopy, Technical University of Denmark, Kgs. Lyngby 2800, \\ DK \\ ${ }^{\mathrm{c}}$ Institute of Materials and Systems for Sustainability, Nagoya University, Nagoya, JP
}

In order to establish the use of solid oxide fuel/electrolysis cells (SOFC/SOEC) in the energy market, a deeper understanding of degradation effects during operation is necessary. This study apply in situ transmission electron microscopy (TEM) of a symmetric model cell composed by two oxygen electrodes of $\mathrm{La}_{0.6} \mathrm{Sr}_{0.4} \mathrm{CoO}_{3-\delta}$ (LSC) and an electrolyte, $\mathrm{ZrO}_{2}: 8 \%$ mol $\mathrm{Y}_{2} \mathrm{O}_{3}$ (8YSZ), deposited on $1 \% \mathrm{Nb}$ doped $\mathrm{SrTiO}_{3-\delta}(\mathrm{STN})$ single crystal substrate by pulsed laser deposition. The results showed a high cation mobility of the electrodes when exposed to $900{ }^{\circ} \mathrm{C}$. Cobalt is found to agglomerate at the interface between LSC and STN. Strontium depletion is observed in both electrodes. Finally, a faster grain growth occurs in LSC for the cell exposed to oxygen in comparison with the cell in vacuum.

\section{Introduction}

Solid oxide cells (SOC) have the potential of playing a significant role in the future efficient energy system scenario. In order for them to become commercially available the cost of SOC has to get lower. This may be accomplished by lowering the operation temperature and improving performance and durability of the cells at the same time (12). In order to do so, a better electrochemical activity of the electrodes and a sufficient low ionic resistance of the electrolyte must be achieved. The use of a mixed ionic and electronic conductor (MIEC) like $\mathrm{La}_{0.6} \mathrm{Sr}_{0.4} \mathrm{CoO}_{3-\delta}$ (LSC) as oxygen electrode showed promising performances when operating at temperatures below $800{ }^{\circ} \mathrm{C}(3-7)$. Moreover, reducing the thickness of the electrolyte results in a low ohmic resistance and thereby improves the performance of the cell (8). To be able to make considerable improvements, it is however an advantage to understand the deterioration mechanisms acting during the operation of the cell. Scanning and transmission electron microscopy (SEM and TEM) have often been used for post mortem characterization of the crucial coupling between degradation and micro- and nanostructure of solid oxide fuel/electrolysis cells SOFCs and SOECs (9-11). However, in order to get fundamental insight into the microstructural development of SOFC/SOEC during operation conditions in situ studies are necessary (12). The development of advanced TEMs and TEM sample holders opens for the possibility to undertake detailed nanoscale analysis of SOFC/SOEC samples in reactive gas flows, at elevated temperatures and with electrochemical polarization. This allows the 
study of nanostructure development under temperature and electrode polarisation conditions.

Before performing an experiment where current, heat and gas are all combined within the TEM, it is beneficial to study the effect of each condition separately. In this article we present an in situ TEM analysis of a symmetric model SOC specimen exposed to elevated temperatures up to $900{ }^{\circ} \mathrm{C}$ (approximate oxygen electrode sintering temperature) in vacuum and in oxygen. A symmetric model SOC with two LSC oxygen electrodes was chosen to conduct an in situ experiment in the environmental TEM (ETEM) with oxygen. Pulsed laser deposition (PLD) was used for the fabrication of the symmetric model SOC. PLD allows the fabrication of thin layers by epitaxial growth. This lead to a high quality interface between electrode and electrolyte with a relatively small amount of impurities and defects (13). These aspects together with the possibility of having dense electrodes provide a lower level of complexity in regards of the sample.

\section{Experimental}

The symmetric cell prepared by PLD is composed of two oxygen electrodes of $\mathrm{La}_{0.6} \mathrm{Sr}_{0.4} \mathrm{CoO}_{3-\delta}$ (LSC) and an electrolyte of $\mathrm{ZrO}_{2}: 8 \%$ mol $\mathrm{Y}_{2} \mathrm{O}_{3}$ (8YSZ). The three thin films were deposited on $1 \%$ Niobium doped $\mathrm{SrTiO}_{3-\delta}$ (STN) single crystal (100) substrate. LSC/YSZ/LSC were grown using a multi-target carousel. The PLD chamber was evacuated to a base vacuum of $1 \times 10^{-8}$ mbar before the deposition. The temperature and the oxygen partial pressure of the substrate during the deposition were $500{ }^{\circ} \mathrm{C}$ and $10^{-4}$ mbar, respectively. A $\mathrm{KrF}$ excimer laser (Coherent Lambda Physik $\mathrm{GmbH}$ ) with a wavelength of $248 \mathrm{~nm}$ and pulse duration of $25 \mathrm{~ns}$ was focused on the target. The laser energy density was kept constant at $4 \mathrm{~J} \mathrm{~cm}^{-2}$ with a repetition rate of $30 \mathrm{~Hz}$. The deposition rate for LSC and YSZ was $0.01 \mathrm{~nm}$ per pulse. These PLD growth conditions should hinder the formation of secondary phases since the deposition temperature is lower than the one reported for the formation of $\mathrm{SrZrO}_{3}$ and $\mathrm{La}_{2} \mathrm{Zr}_{2} \mathrm{O}_{7}$ (14).

The TEM specimen was prepared by focused ion beam (FIB) in a FIB-SEM, a Zeiss Crossbeam 1540XB equipped with a field-emission gun. The FIB was operated at $30 \mathrm{kV}$ during milling. The specimen was attached by $\mathrm{Pt}$ on a Molybdenum grid for all the experiments conducted in vacuum and on a stainless steel grid for the experiments conducted in oxygen. The FIB milling was done in several steps subsequently decreasing the probe size down to $50 \mathrm{pA}$ in the final preparation stage. All the specimens prepared by the FIB and analyzed in this work are extracted from the same symmetric SOC.

A JEOL 3000F equipped with a $300 \mathrm{kV}$ FEG, a scanning unit (STEM) and a highangle annular dark-field (HAADF) detector was used for post-mortem analysis and for in-situ heating experiment in vacuum, where the temperature of $900{ }^{\circ} \mathrm{C}$ was reached. A Gatan single tilt heating holder (Model 628) was used to heat the sample. In this experiment, the temperature was ramped in steps of $100{ }^{\circ} \mathrm{C}$ with a heating rate of 10 ${ }^{\circ} \mathrm{C} / \mathrm{min}$, and at each temperature step the specimen was kept at constant temperature for approximately an hour to allow the system and cell to stabilize and to record images. The temperature was measured by a thermocouple welded to the furnace in the heating holder.

Energy-dispersive X-ray spectroscopy (EDS) was carried out for compositional analysis at room temperature by an Oxford Instruments detector with an ultra-thin window. The analysis was performed using the Inca software.

Environmental TEM (ETEM) was performed at $300 \mathrm{kV}$ using a Titan 80-300 (FEI) equipped with a differential pumping system and an aberration corrector (15). The samples were exposed to 2 mbar of $\mathrm{O}_{2}$ (AGA 6.0) and a Gatan double tilt heating TEM 
holder was used to heat the specimen. The same experimental conditions were applied as described for the experiment conducted in vacuum.

Energy-filtered TEM was done at $1 \mathrm{MV}$ with a JEOL reaction science highvoltage electron microscope (RSHVEM) equipped with a Gatan imaging filter (GIF) (16).

The average grain size of the new phases formed was estimated from the recorded images at different temperatures from a sample area of $4 \mathrm{x} 0.8 \mu \mathrm{m}$, based on measurements of 50 grains. The estimation of the size of individual grains was manually done by drawing a line across the specific site. The software used was Gatan's Digital Micrograph $^{\mathrm{TM}}$. The average grain size was determined from the images acquired at each temperature throughout the entire heating experiment both in vacuum and in oxygen. The standard deviation was calculated to indicate the dispersion of the data.

\section{Results and discussion}

\section{$\underline{\text { Room temperature characterization }}$}

Before conducting the actual in situ TEM experiment, the symmetric SOC model was analyzed ex situ. Figure 1 shows a high angle annular dark field (HAADF) STEM image of the sample cross section. All layers are dense and no delamination of the layers is observed. In figure 1 the two LSC layers are labelled LSC1 and LSC2. The microstructure of LSC1 is single crystalline, whereas LSC2 presents a column-like structure which indicates grains of column-like morphology with diameters of 10-30 nm (Figure 1). This is often observed when the deposition is made on a substrate with different crystallinity or chemical bounding (17). This columnar growth of LSC prepared by PLD has previously been described (18-20).

It is well known that LSC and YSZ forms insulating second phase compounds such as $\mathrm{SrZrO}_{3}$ or $\mathrm{La}_{2} \mathrm{ZrO}_{7}$ during the usually applied sintering process at high temperatures (above $900{ }^{\circ} \mathrm{C}$ ) in air, these are insulating phases (21-22). In our symmetric model cell, the PLD preparation was carried out at $500{ }^{\circ} \mathrm{C}$, and therefore no second phase should be formed. Figure 2a) presents a high resolution TEM (HRTEM) image of the interface between YSZ and LSC2. A Fast Fourier Transform (FFT) analysis of the image presented in figure $2 b-c$, shows that the observed lattices are consistent with cubic YSZ at the left side of the interface and a rhombohedral LSC2 at the right side. All observed lattice planes are consistent with YSZ and LSC (figure 2d) and there is therefore no indication of second phase formation at or near the YSZ-LSC2 interface. 


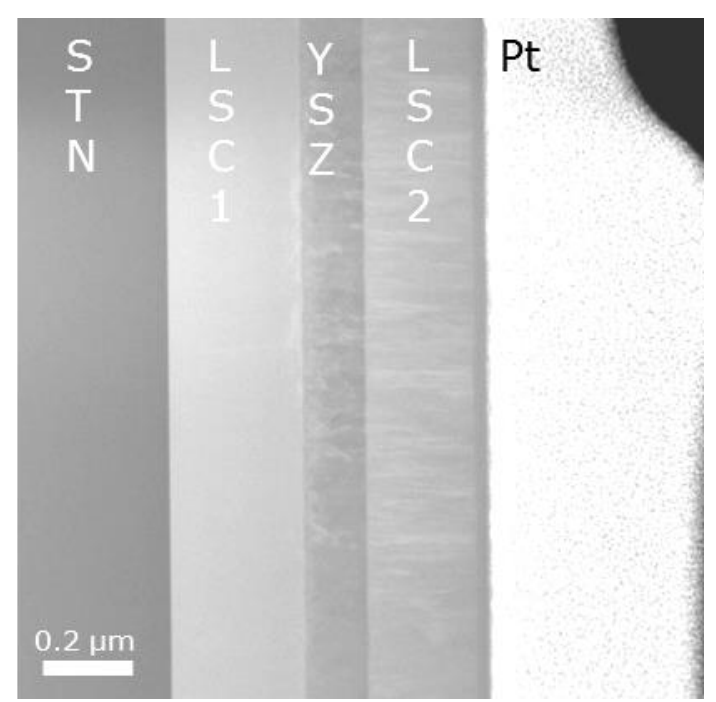

Figure 1. HAADF STEM image of a cross section of the symmetric model cell. LSC1 refers to the first LSC layer which was grown directly at the STN support. LSC2 refer to the second LSC layer grown on top of the YSZ electrolyte. LSC1 is homogenous and LSC2 has a microstructure of columns along the PLD growth direction.
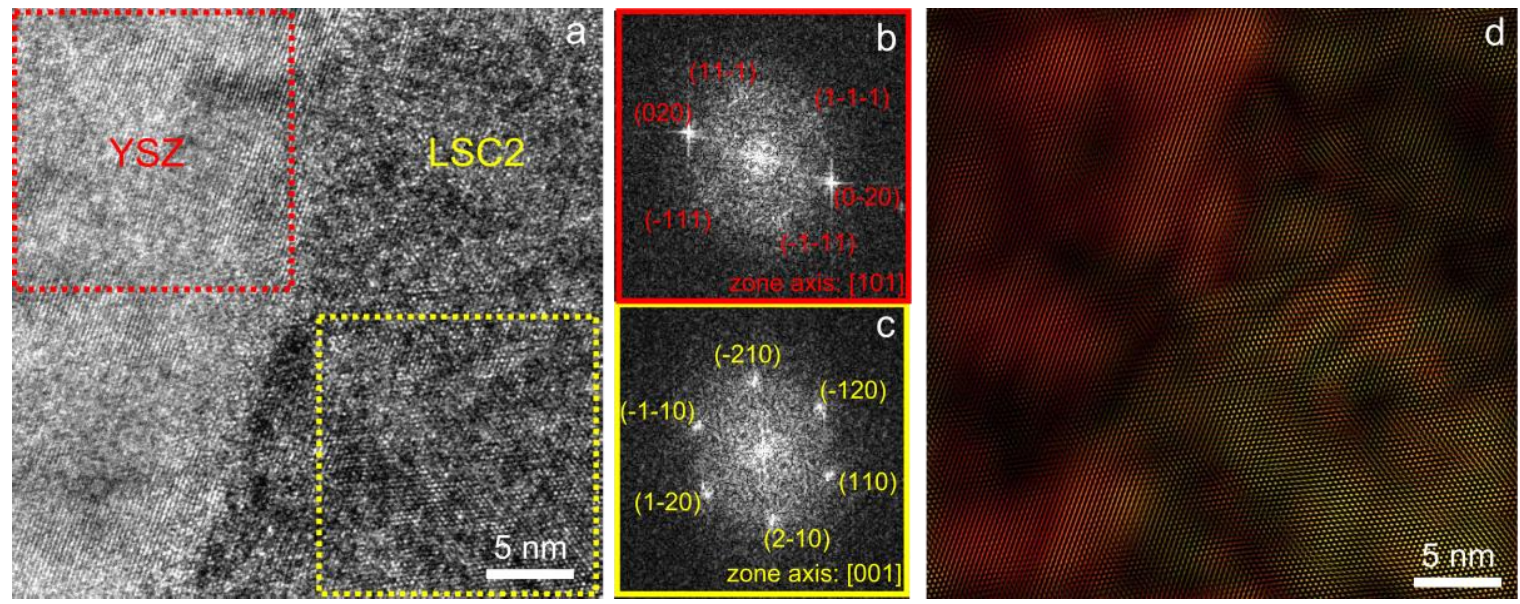

Figure 2(a-d). (a) HRTEM image of the interface between YSZ and LSC2. (b) Fast Fourier Transform (FFT) from an area (top left) at the YSZ-side of the interface. (c) FFT from an area (bottom right) at the LSC2-side of the interface. Bright spots in the FFTs, corresponding to lattice planes visible in the HRTEM image, are analyzed confirming that all observed spots at the YSZ-side are consistent with YSZ and all spots observed at the LSC2-side are consistent with LSC. Miller indices and zone axis are assigned for each crystal (b-c). An FFT of the entire HRTEM image (a) was calculated and two inverse FFTs were produced after applying a mask covering everything else but the spots from YSZ (red) or LSC2 (yellow). (d) Presents these two FFTs over layered, where red color represents YSZ and yellow color represents LSC.

Figure 3 shows the composition profiles of $\mathrm{La}, \mathrm{Sr}, \mathrm{Zr}$ and $\mathrm{Co}$ along the two interfaces of LSC1-YSZ and LSC2-YSZ as obtained from a STEM-EDS line scan. The inset represents the scan path taken into consideration. No clear second phase formation at the interfaces is observed. 


\section{LSC1 YSZ LSC2}

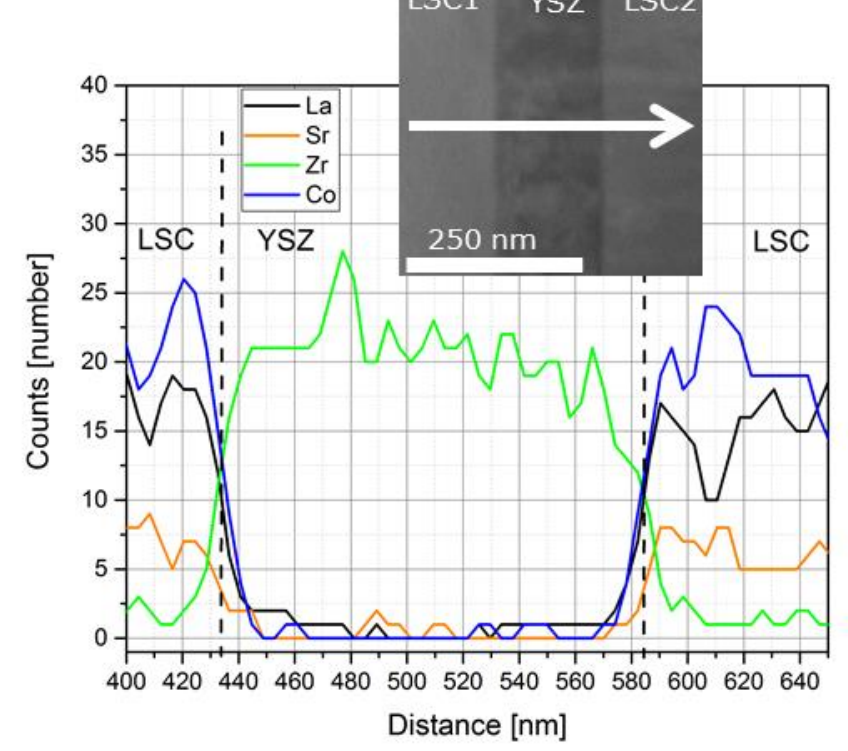

Figure 3. STEM-EDS line scan for Co K-alpha, Sr K-alpha, Zr K-alpha and La L-alpha $\mathrm{X}$-ray signal among LSC1, YSZ and LSC2. The inset represents a HAADF-STEM image and the arrow indicates the scan path. The dotted vertical lines in the graph indicate the interfaces.

\section{In situ heating experiment}

The specimen was exposed to increasing temperatures starting from room temperature to $900{ }^{\circ} \mathrm{C}$ in vacuum. With the increase of temperature, segregation of compounds started to form in the LSC1 layer. These segregations grew in size until the maximum temperature of $900{ }^{\circ} \mathrm{C}$ was reached. At this point formation of nanopores was also observed (figure $4 \mathrm{a}$ white spots close to LSC1-YSZ interface). The average size of these pores is about $50 \mathrm{~nm}$ with a standard deviation of $8 \mathrm{~nm}$. Post mortem energyfiltered TEM (EFTEM) and STEM-EDS analysis, of the specimen exposed to $900{ }^{\circ} \mathrm{C}$, shows pronounced cation mobility along the electrode. Figure $4 \mathrm{~b}$ presents an EFTEM image around the cobalt $\mathrm{L}_{23}$ edge. The figure reveals cobalt agglomeration at the interface between LSC1 and STN, indicated by arrows. Surprisingly, almost no cobalt is present in LSC2. It appears that the majority of the Co has migrated from both LSC1 and LSC2, in the latter case crossing the YSZ, and to agglomerate at the LSC1-STN interface. 


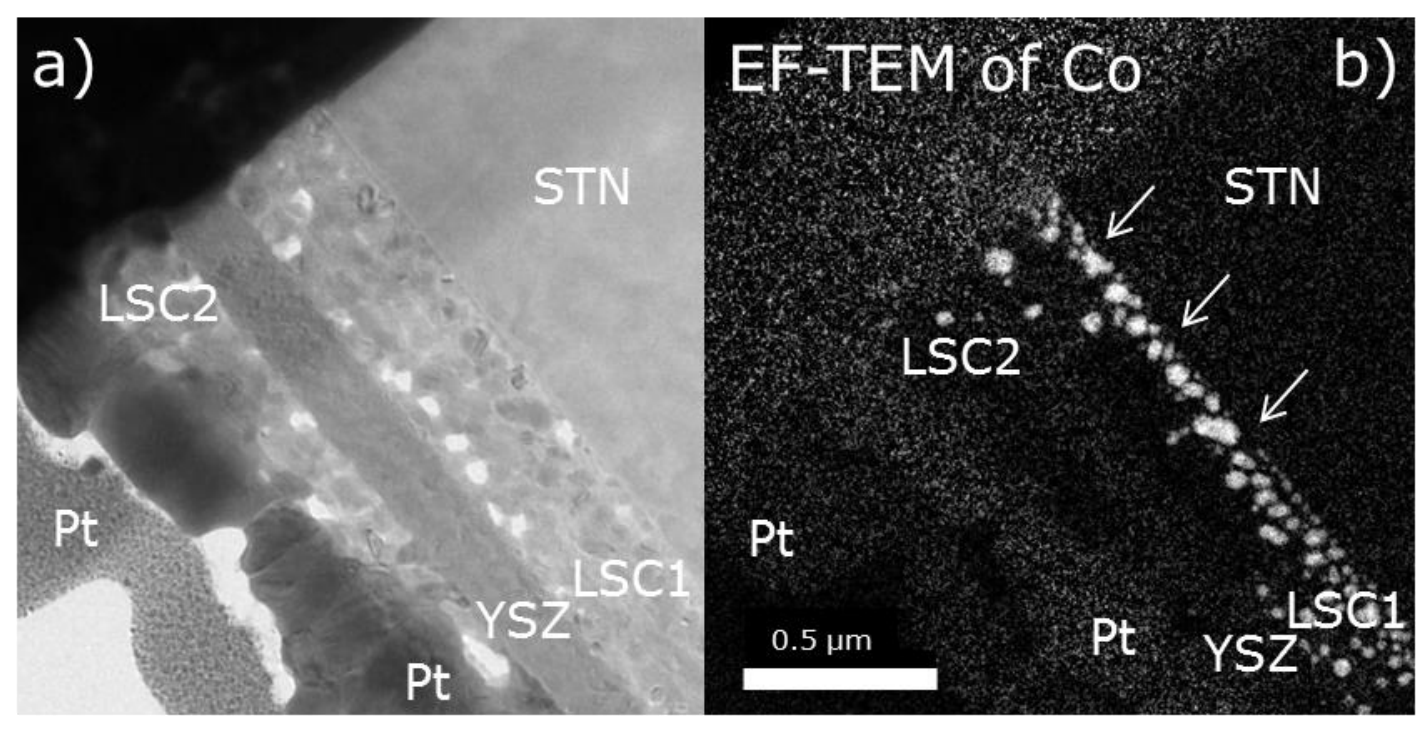

Figure 4. a) BF-STEM image recorded with a JEOL RSHVEM. b) Energy-filtered TEM image using the $L_{23}$ edge of cobalt with an energy slit from 715 to $736 \mathrm{eV}$. The arrows indicate Co agglomerations. The scale bar is applicable for both image a) and b).

Cobalt depletion from LSC in low oxygen partial pressure was reported previously. For instance, Ovenstone et al. (23) reported that in reducing conditions $\left(4 \% \mathrm{H}_{2}\right.$ in $\left.\mathrm{N}_{2}\right)$, at temperatures above $675^{\circ} \mathrm{C}$, a LSC pellet decomposed to $\mathrm{La}_{2} \mathrm{O}_{3}, \mathrm{SrO}$ and Co metal, where they remained stable up to $1000{ }^{\circ} \mathrm{C}$ and upon cooling to room temperature. Figure $5 \mathrm{a}$ shows a HAADF STEM image and Figure 5b an STEM-EDS elemental map of the Co signal in the region of Co agglomeration at LSC1 near the LSC1-STN interface.

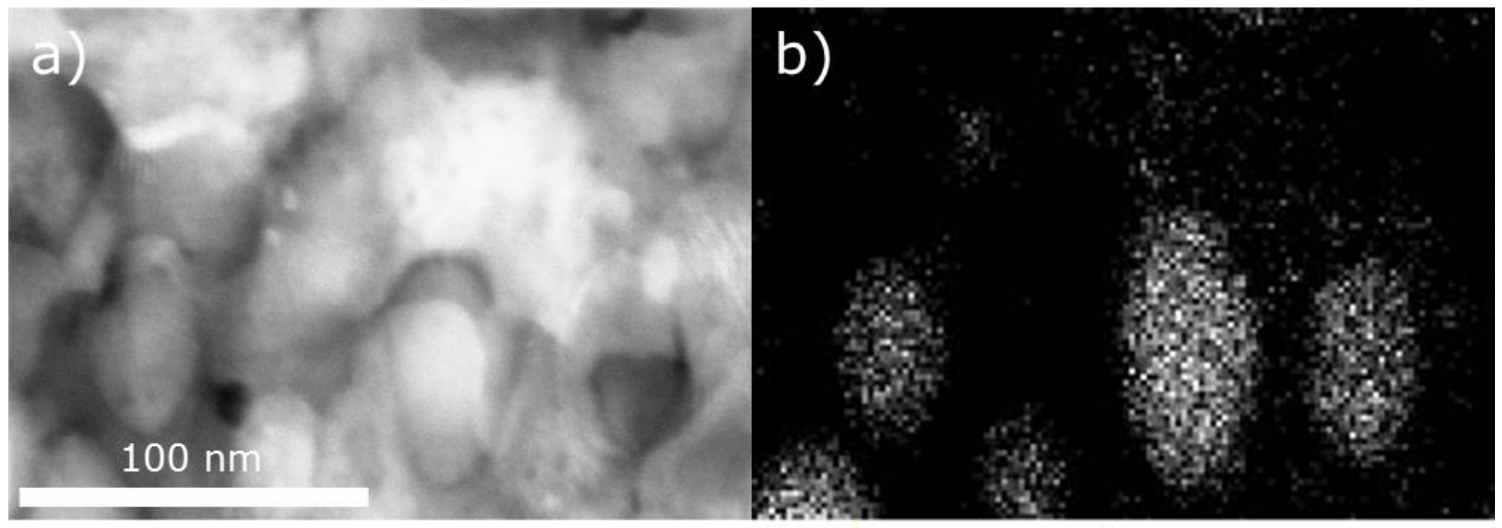

Figure 5 a) HAADF STEM image of LSC1 near the interface to STN after heating at 900 ${ }^{\circ} \mathrm{C}$ in vacuum. b) STEM-EDS elemental map of cobalt K-alpha X-ray signal from the same area as (a).

Figure 6a presents an EFTEM image around the $\mathrm{L}_{23}$ edge of Sr. According to this figure most of the Sr migrated from the LSC electrodes to the STN and into the YSZ layer. Figure $6 \mathrm{~b}$ presents a HAADF STEM image, which gives a more detailed view of the interface between YSZ and LSC1, indicated by the dashed line. From the elemental map in figure $6 \mathrm{c} \mathrm{Sr}$ is found at the interface where it probably reacted with $\mathrm{Zr}$ to form $\mathrm{SrZrO}_{3}$ (21-22). 


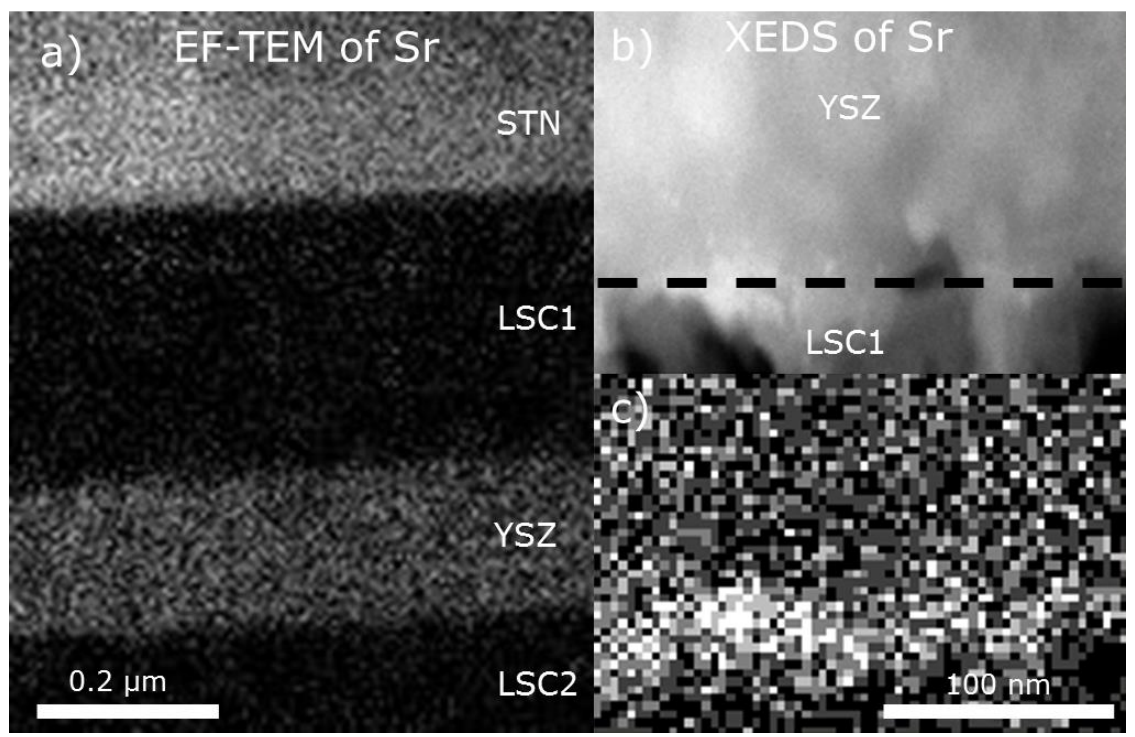

Figure 6 a) EFTEM image using the $\mathrm{L}_{23}$ edge of Sr with an energy slit from 260 to 264 eV. b) HAADF STEM image, with dash line indicating the interface between LSC1 and YSZ. c) STEM-EDS elemental map of the interface between YSZ and LSC1 for the Sr $\mathrm{K}$-alpha X-ray signal.

In situ heating experiment in vacuum and in oxygen

Another symmetrical model specimen coming from the same sample batch was used for a subsequent in situ heating experiment in vacuum. Here the maximum temperature was $800{ }^{\circ} \mathrm{C}$. This experiment showed the same structural development as observed in the first heating experiment. Figure 8, top part, presents a series of images acquired at different temperatures in vacuum. In vacuum, the microstructure of the layers remained unchanged up to $600{ }^{\circ} \mathrm{C}$. At $700{ }^{\circ} \mathrm{C}$, round nano-grains start to form in the LSC layers. At $800{ }^{\circ} \mathrm{C}$, the size of the grains kept growing in size. Nanopores were also observed. A similar experiment was conducted in oxygen, where the total pressure was kept at 2 mbar (figure 8, button part). In oxygen at $600{ }^{\circ} \mathrm{C}$, grains in the LSC layers, are already visible. These grains grew until the maximum temperature of $800{ }^{\circ} \mathrm{C}$ is reached. A previous work from Kubicek et al. (18) found that in air the cation diffusion at the grain boundaries is three orders of magnitude faster than inside the grains. In the present specimen, there are two different nanostructures of LSC, a single crystal (LSC1) and a column-like (LSC2). Therefore, if we consider the specimen exposed to oxygen, it is expected that LSC2 with the column-like structure would have a higher cation diffusion rate due to the presence of grain boundaries. On the other hand, LSC1 is a single crystal with no grain boundaries, so the cation diffusion according to Kubicek et al. should be significantly lower. However, this behavior is not observed here. Instead LSC1 presented a faster segregation than LSC2. It should, however, be noted that the TEM sample was prepared to a thickness of ca. $100 \mathrm{~nm}$, so both LSC1 and LSC2 are exposed to oxygen from the surfaces normal to the direction of the electron beam. This equal access to oxygen could possibly explain the similar growth rates. Some differences can, on the other hand, be observed between LSC1 and LSC2: figure 9 illustrates that already at $200{ }^{\circ} \mathrm{C} \mathrm{LSC1}$ surprisingly manifested nano-grains (indicated by white arrows), in particular in an area close to the thicker part of the specimen, whereas in LSC2 no appreciable grain formation was observed. In the figure 9, the grains appear as white spots. This difference is even clearer at $300{ }^{\circ} \mathrm{C}$, when in LSC1 more grains are formed close to the interface with the STN (indicated by white 
arrows). In the temperature range between $600{ }^{\circ} \mathrm{C}$ and $650{ }^{\circ} \mathrm{C}$, the difference in grain size is no more appreciable. For the specimen heated in vacuum this different behavior between the two electrodes was not observed.

Figure 10 shows a comparison of average grain size between the experiment conducted in vacuum and the one conducted in oxygen. The experiment in oxygen contains values for both LSC1 and LSC2. The difference in grain size between LSC1 and LSC2 is minimal and already at $600{ }^{\circ} \mathrm{C}$ it can be considered the same.

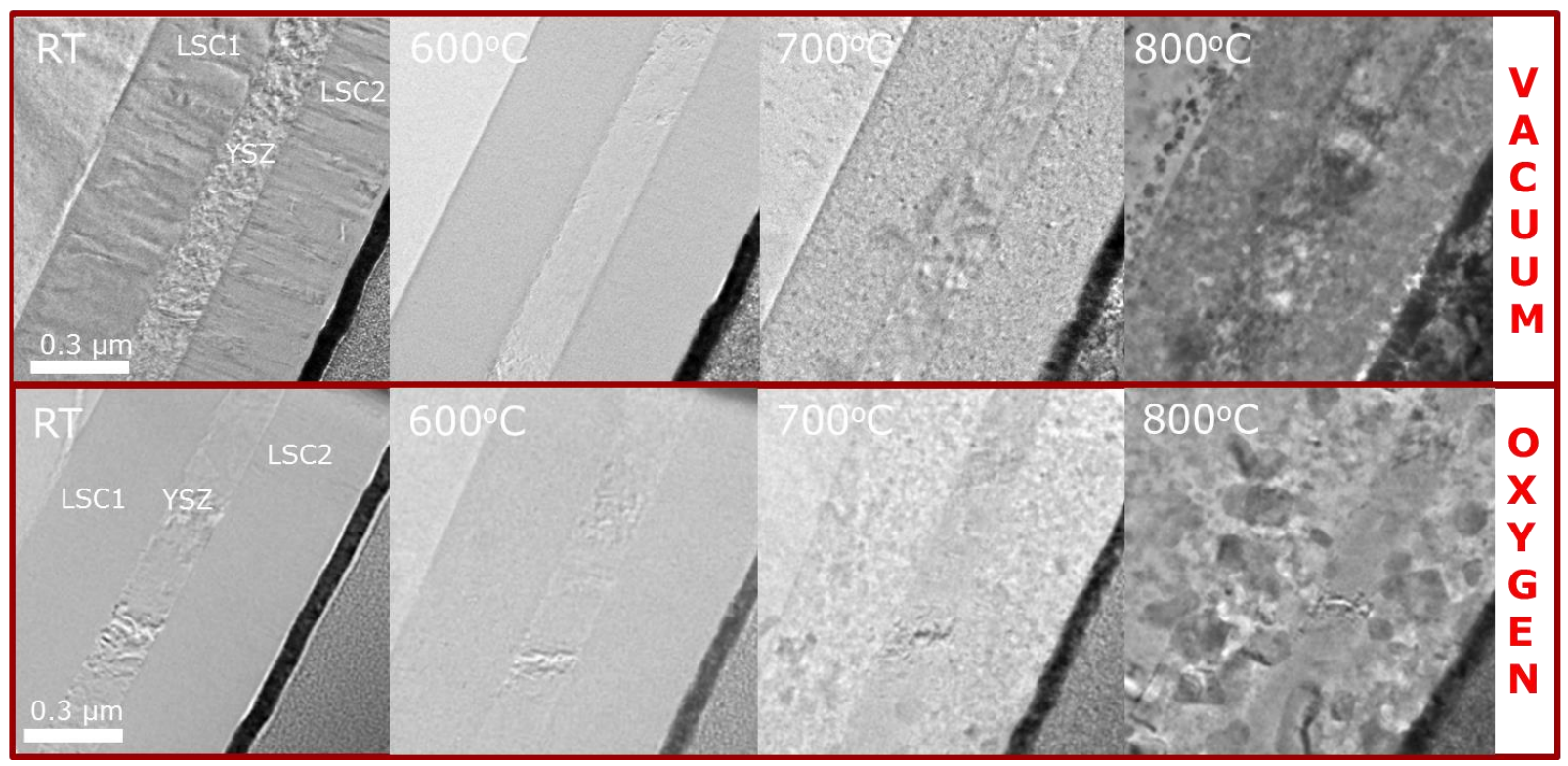

Figure 8 A series of in situ TEM images recorded at different temperatures in vacuum at a total pressure of $7.8 \times 10^{-7}$ mbar and in oxygen at a total pressure of 2 mbar.

In oxygen already at $200{ }^{\circ} \mathrm{C}$ small grains are observed, whereas in vacuum only at $600{ }^{\circ} \mathrm{C}$ round nano-grains can be clearly detected. The average grain size is similar for the two experiments at $600{ }^{\circ} \mathrm{C}$. At $800{ }^{\circ} \mathrm{C}$, the average grain size in oxygen are much larger than the one in vacuum. These results are in agreement with the work done by Palcut et al. (23). They showed that for polycrystalline pellets of $\mathrm{La}_{2} \mathrm{O}_{3}$ and $\mathrm{CoO}$, the solid state reaction $\mathrm{La}_{2} \mathrm{O}_{3}$ and $\mathrm{CoO}$ was faster at higher oxygen partial pressure. They demonstrated that the kinetic reaction is governed by the Co cation diffusion though the vacancies. With the increase of the oxygen partial pressure, the amount of cobalt vacancies increases leading to a faster cation diffusion.

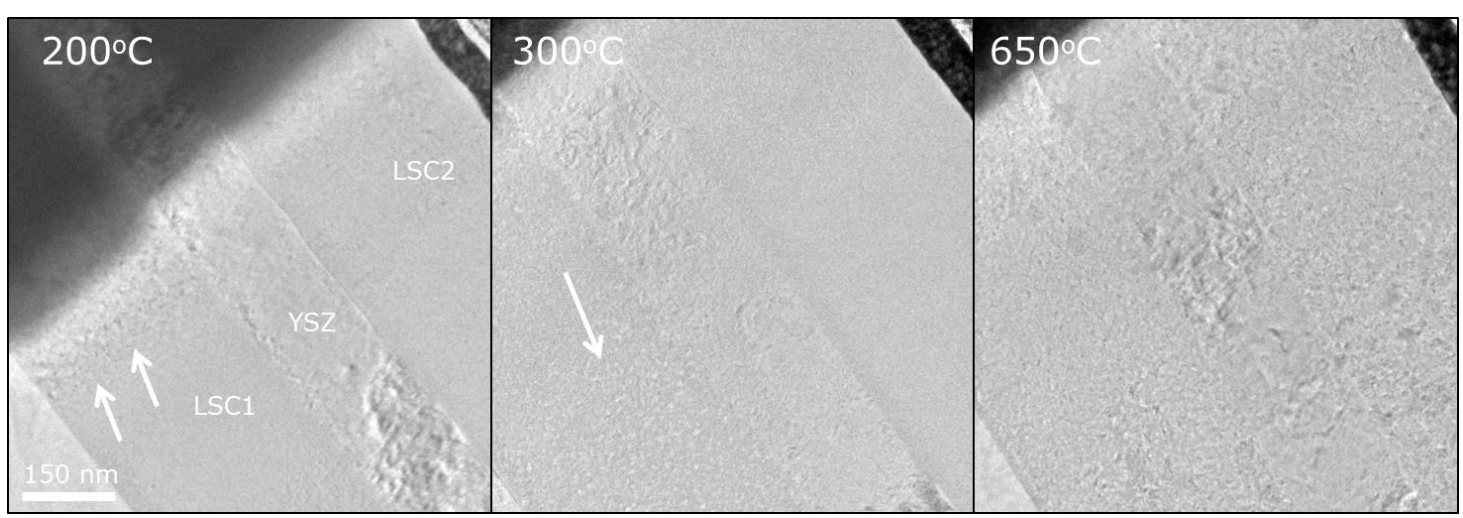

Figure 9 A series of in situ TEM images recorded at different temperatures in oxygen at a total pressure of 2 mbar. 
Further analysis is needed to fully understand the real process behind the faster grain growth in oxygen for the thin layer of dense LSC.

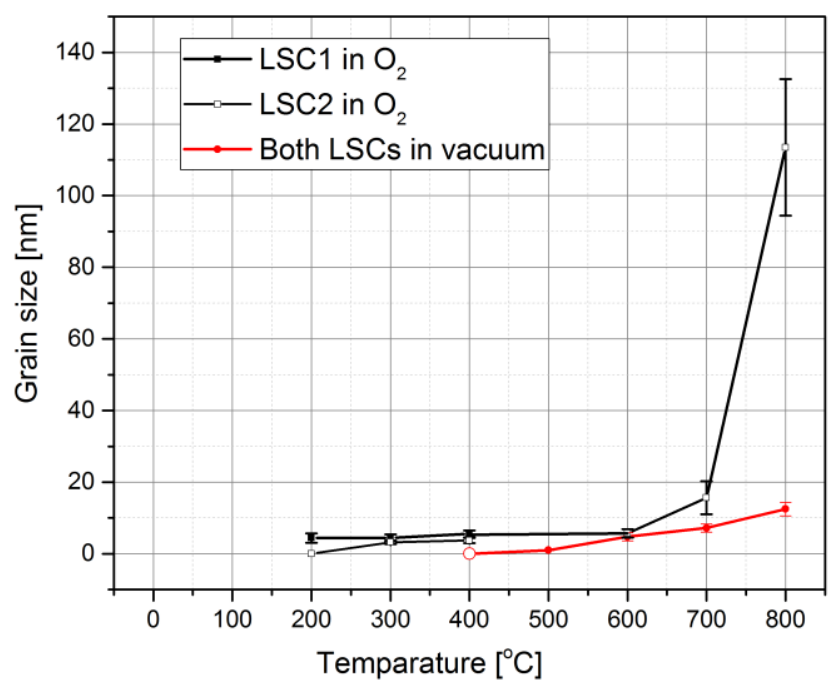

Figure 10 Average grain size estimation in LSC electrodes as a function of temperature for in situ TEM heating experiments conducted in vacuum and in 2 mbar oxygen. For the experiment conducted in oxygen both LSC1 and LSC2 are showed. The empty circle for the vacuum set of data means that no measurable grains were found. Error bars indicate the standard deviation.

\section{Conclusion and outlook}

An in situ TEM study of a model symmetric solid oxide cell in different environmental conditions was performed. When the sample was exposed to $900{ }^{\circ} \mathrm{C}$ in vacuum, a massive diffusion of cobalt to the interface between STN and LSC1 was observed. Moreover, starting from a sample with no visible second phase formation at the interface between LSC electrodes and YSZ, as showed from HR-TEM and STEM-EDS analysis, after the experiment at $900{ }^{\circ} \mathrm{C}$ in vacuum, depletion of $\mathrm{Sr}$ was observed and its agglomeration at the interface with YSZ was found. Therefore, at this temperature, LSC is very unstable and it undergoes fast deterioration process and this is deleterious for the durability of the cell and its performances.

Two similar experiments were implemented under different environmental conditions, one in oxygen and the other one in vacuum. Where for the sample in vacuum, the microstructure remained unchanged up to $600{ }^{\circ} \mathrm{C}$, in oxygen round nano-grains were observed already at $200{ }^{\circ} \mathrm{C}$. At the final temperature of $800{ }^{\circ} \mathrm{C}$ the grain size for the sample exposed to oxygen it reached approximately $100 \mathrm{~nm}$ whereas the grain size for the sample exposed to vacuum was around $10 \mathrm{~nm}$.

\section{Acknowledgments}


We gratefully acknowledge financial support of this research from In Situ Transmission Electron Microscopy on Operating Electrochemical Cells (TEMOC) project, supported by the Danish Council for Independent Research grant no. DFF 4005-00247. E. Abdellahi from DTU Energy for the initial sample preparation and Nagoya University microstructural characterization platform for taking EF-TEM images.

\section{References}

1. A. Atkinson, S. Barnett, R. J. Gorte, J. T. S. Irvine, A. J. Mcevoy, M. Mogensen, S. C. Singhal, and J. Vohs, Nature Materials, 3, (2004).

2. C. Graves, S. D. Ebbesen, S. H. Jensen, S. B. Simonsen, and M. B. Mogensen, Nature Materials, 14, (2010).

3. A. Ringuedé and J. Fouletier, Solid State Ionics, 139, (2001).

4. J. Hayd, U. Guntow, and E. Ivers-Tiffée, ECS Trans., 35, (2011)

5. H. Y. Jung, K.-S. Hong, H.-G. Jung, H. Kim, H.-R. Kim, J.-W. Son, J. Kim, H.-W. Lee, and J.-H. Lee, J. Electrochem. Soc., 154, (2007).

6. C. Peters, A. Weber, and E. Ivers-Tiffée, J. Electrochem. Soc., 155, (2008).

7. H.-G. Jung, Y.-K. Sun, H. Y. Jung, J. S. Park, H.-R. Kim, G.-H. Kim, H.-W. Lee, and J.-H. Lee, Solid State Ionics, 179, (2008).

8. E. Ivers-Tiffée, J. Hayd, D. Klotz, A. Leonide, F. Han and A. Weber., ECS Trans, 35, (2011).

9. R. Knibbe, M. L. Traulsen, A. Hauch, S. D. Ebbesen, and M. Mogensen, J. Electrochem. Soc., 157, (2010).

10. N. Imanishi, Y. Sumiya, K. Yoshimura, T. Matsumura, A. Hirano, Y. Takeda, D. Mori, and R. Kanno, Solid State Ionics, 177, (2006).

11. K. V. Hansen, M. Chen, T. Jacobsen, K. Thydén, S. B. Simonsen, S. Koch, and M. B. Mogensen, J. Electrochem. Soc., 163, (2016).

12. M. L. Traulsen, C. Chatzichristodoulou, K. V. Hansen, L. T. Kuhn, P. Holtappels, M. B. Mogensen, ECS Trans, 66, (2015).

13. V. Esposito, I. Garbayo, S. Linderoth, and N. Pryds, Solid-oxide fuel cells, p 443478, Elsevier Ltd , (2015).

14. H. Yokokawa, T. Horita, High Temperature Solid Oxide Fuel Cells Fundamentals, Design and Application, p. 119-147, Elsevier Ltd, (2003).

15. T. W. Hansen, J. B. Wagner, and R. E. Dunin-Borkowski, Mater. Sci. Technol., 26, (2010).

16. N. Tanaka, J. Usukura, M. Kusunoki, Y. Saito, K. Sasaki, T. Tanji, S. Muto, and S. Arai, J. Electron Microsc., 62, (2013).

17. S. Sanna, V. Esposito, D. Pergolesi, A. Orsini, A. Tebano, S. Licoccia, G. Balestrino, and E. Traversa, Adv. Funct. Mater., 19, (2009).

18. M. Kubicek, G. M. Rupp, S. Huber, A. Penn, A. K. Opitz, J. Bernardi, M. StögerPollach, H. Hutter, and J. Fleig, Phys. Chem. Chem. Phys., 16, (2014).

19. P. Plonczak, A. Bieberle-Huetter, M. Søaard, T. Ryll, J. Martynczuk, P. V. Hendriksen, and L. J. Gauckler, Adv. Funct. Mater., vol. 21, (2011).

20. I. Garbayo, V. Esposito, S. Sanna, A. Morata, D. Pla, L. Fonseca, N. Sabaté, and A. Tarancón, J. Power Sources, 248, (2014). 
21. L. Dieterle, D. Bach, R. Schneider, H. Störmer, D. Gerthsen, U. Guntow, E. IversTiffée, A. Weber, C. Peters, and H. Yokokawa, J. Mater. Sci., 43, (2008).

22. M. Sase, D. Ueno, K. Yashiro, A. Kaimai, T. Kawada, and J. Mizusaki, J. Phys. Chem. Solids, 66, (2005).

23. J. Ovenstone, J. S. White, and S. T. Misture, J. Power Sources, 181, (2008).

24. M. Palcut, K. Wiik, and T. Grande, J. Phys. Chem. B, 111, (2007) 